\title{
GALLOPING OF OVERHEAD POWER LINES CONDUCTORS
}

\author{
I. Gołębiowska $^{*}$, M. Dutkiewicz ${ }^{* *}$, B. Usewicz ${ }^{* *}$
}

\begin{abstract}
Limiting the risk of damage to overhead power line conductors covered with ice due to wind is crucial both for safety of the whole system and for economical reasons. The article concentrates on causes of the galloping effect and the phenomenon itself. Aerodynamic - structural methods which reduce the level of vibrations caused by the above phenomenon are described herein.
\end{abstract}

Keywords: antigalloping devices, power lines, iced conductors

\section{Introduction}

An overhead power lines is a set of single conductors or conductor bundles, ground wires, isolators, supporting structures, fittings and other components specific to its operation. Conductors serve to transmit electric power and are connected to towers with isolators. Ground wires protect the line from lightning strikes. Due to the nature of their operation, conductors should have a great tensile strength, high conductivity and excellent resistance to weather conditions. Steel and aluminium conductors are most commonly used in overhead power lines. The conductor core consists of one or a few galvanised steel wires. Layers of aluminium wires are winded torsionally around the conductor core. In such a conductor, current is conducted by the external aluminium braid ensuring high conductivity, whereas the steel core distinguished by its high tension strength absorbs the majority of tension. In extra high voltage power lines, wire bundles used mainly to limit corona discharges, reduce reactance and increase power line transmission capacity apply (Stabiloy, 2016).

Conductors are very flexible structural components characterised by a very low internal damping level, thus are susceptible to dynamic excitations caused by wind, etc. Vibrations of overhead power lines caused by wind occur at the following frequencies: at low 0.1-1 Hz (the galloping effect) to high 3-150 $\mathrm{Hz}$ (aeolian vibrations); for a conductor bundles - wake induced vibrations (a flatter-type instability caused by a coupling of horizontal and vertical form of vibrations) at an average frequency of $0.15-10$ Hz. The above types of vibrations are hazardous because they may result in fatigue destruction and fretting (damage of wires having contact in a conductor caused by surface motion) and even in conductor rupture (PES-TR17, 2015).

In order to properly protect conductors from vibrations, it is necessary to understand physical phenomena causing them.

The article focuses on the galloping effect and its causes, occurring on single conductors and conductor bundles covered with ice. Aerodynamic structural methods which can effectively reduce the level of hazardous vibrations caused by the above phenomenon are described as well.

Prof. Dr. Eng. Irena Gołębiowska, Department of Building Construction, University of Science and Technology in Bydgoszcz, Al. Prof. S. Kaliskiego 7, 85-796 Bydgoszcz PL, e-mail: irena_golebiowska@wp.pl

** Dr. Eng. Maciej Dutkiewicz, Department of Building Construction, University of Science and Technology in Bydgoszcz, Al. Prof. S. Kaliskiego 7, 85-796 Bydgoszcz PL, e-mail: macdut@utp.edu.pl

*** Eng. Bogdan Usewicz, Department of Building Construction, University of Science and Technology in Bydgoszcz, Al. Prof. S. Kaliskiego 7, 85-796 Bydgoszcz PL 


\section{Icing of conductors}

Vibrations of overhead power lines may be caused by wind alone, an interaction of wind with ice deposits and may occur when removing ice from conductors. The galloping effect occurring on conductors (single or conductor bundles) covered with ice is the most hazardous type of vibrations for overhead power lines. Large amplitude oscillation at low frequencies or also twisting due to asymmetrical icing of conductors can cause fatigue damages in extreme accidents of atmospheric icing can cause severe damage on towers and/or power lines. Ice and snow on conductors may come from cloud droplets, raindrops, snow or water vapour. Depending on weather conditions atmospheric icing can be classified as follows (Fikke, 2007a,b) (Fig. 1a): in-cloud icing, precipitation icing, hoar frost.

According to Farzaneh (2008) atmospheric icing can be defined as any process of ice build up and snow accretion on the surface of an object exposed to the atmosphere.

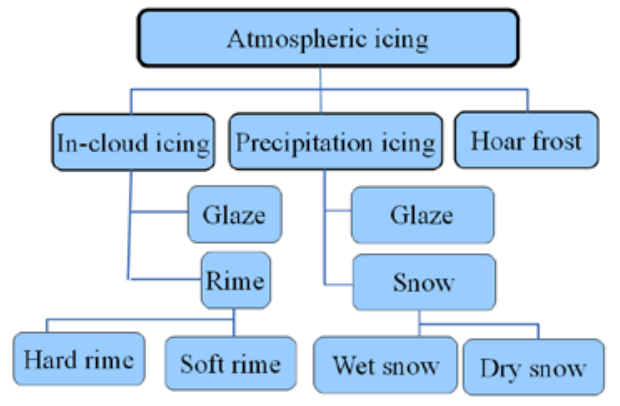

(a)

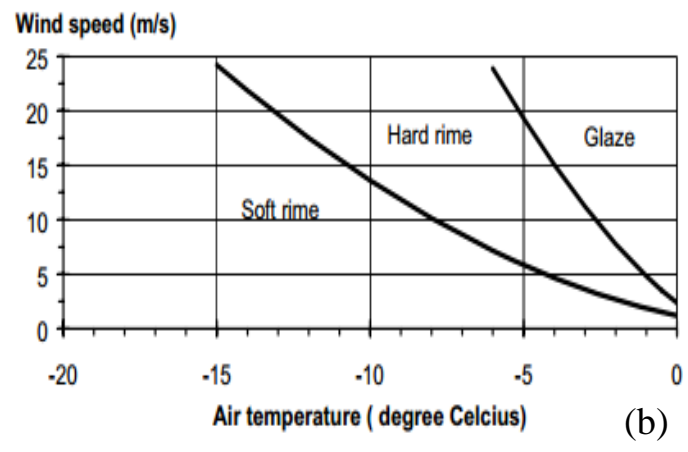

(b)

Fig. 1: (a) ice types, (b) type of accreted ice as a function of wind speed and air temperature (Fikke, 2007a)

Ice accretion is formed when cold water drops hit and adhere to a surface of a freezing temperature or temperature below this point. Atmospheric icing is controlled mainly by four parameters such as: air temperature, wind speed, drop size, liquid water content (the mass of water per unit volume of air).

Wet snow is, because of the occurrence of free water in the partly melted snow crystals able to adhere to the surface of a conductor (Fikke, 2007a). It forms various shapes dependent on wind velocity and torsional stiffness of the conductor. Wet snow may easily slip off or if there is a temperature drop after accretion, it may have very strong adhesion. These conditions dependent on temperature (Fikke, 2007b). Dry snow (density 50 to $100 \mathrm{~kg} / \mathrm{m}^{3}$ ) is a very light pack of regular snow, which is easily removed by shaking the conductor. Hoar frost, which is due to direct phase transition from water vapour into ice, is common at low temperatures. Hoar frost is of low density (50 to $300 \mathrm{~kg} / \mathrm{m}^{3}$ ) and strength, and normally does not result in significant load on conductors. It is white and fragile. Fig. 1b presents types of ice accretion by temperature and wind speed. As far as ice accretion is concerned, each type of accretion which modifies the conductor cross section may contribute to galloping. However, wet snow and freezing rain are most commonly associated with galloping (Nigol, 1974).

Torsional stiffness of a conductor determines torsion capacities and has a huge influence on the shape of a cross section of ice accretion which covers the conductor. For conductors with low torsional stiffness, ice accretion forms sleeves around the conductor. On conductors with higher torsional stiffness, ice accretion occurs on the windward side and the geometry is no longer cylindrical. Long span conductors and/or conductors of a small cross section have a low torsional stiffness, thus they are subject to torsion. Torsional stiffness depends not only on the conductor diameter and material but also on tension.

In conductor bundles, tension of each sub-conductor is different. The number of sub-conductors in a bundles, a distance between them and spacers affect torsional characteristics of such sub-conductors. On conductors in a bundles with a higher torsional stiffness, ice accretion is formed in the shape more susceptible to galloping than for a single conductor. Loading a conductor with ice and snow increases its tension, thus reduces its internal damping. Furthermore, ice may 'glue' conductor wires to decrease its damping parameters. Even ice accretion of a few millimetres, which sometimes is hard to notice, may be 
sufficient to cause galloping. The accumulation of atmospheric ice on power transmission lines can be a source of tremendous damage to power network.

\section{Galloping}

The presence of ice on the conductor surface changes its cross shape from symmetric to asymmetric, causing its aerodynamical instability. When the ice layer grows (mainly on the top windward side of the conductor), the natural frequency is reduced and when this frequency gets close to one of the lower natural frequency of vertical vibrations, galloping occurs. For an angle of attack of approx. $45^{\circ}$, a curve of the lift coefficient reaches it maximum value, and wind lifts the conductor (Nigol, 1974). When the conductor is twisted, the wind force acts downwards, leading to an increase of the amplitude of vibrations in the vertical plane during galloping (Luongo, 2009). Fig. 2 shows the effect of aerodynamic lift, drag and moment coefficients to a conductor covered with ice.

Galloping is a typical instability caused by a coupling of aerodynamic forces which affect a conductor with vibrations. Conductor vibrations change the wind angle of attack on a periodic basis. Such a change modifies aerodynamic forces affecting the conductor, resulting in a change of conductor response. The first simplified criterion, at a model of single degree of freedom - 1 DOF, concerning instability related to galloping was presented by Den Hartog (1932):

$$
\left(\frac{\mathrm{dC}_{\mathrm{L}}}{\mathrm{d} \alpha}+\mathrm{C}_{\mathrm{D}}\right)_{\alpha=0}<0
$$

where: $\alpha$ is the angle of attack in degrees, $C_{L}$ is the aerodynamic lift coefficient and $C_{D}$ is the aerodynamic drag coefficient.

A precondition for galloping (according to the quasi-steady theory) is negative aerodynamic damping in the system. The Den Hartog stability criterion expresses negative aerodynamic damping caused by a significant reduction of lift force coefficients along with an increase of the angle of attack. Works carried out by Hartog indicate that the aerodynamic instability is the main reason for galloping. His research was conducted with an assumption that the vertical movement of a conductor is dominant and the influence of torsional and horizontal motions can be ignored. Another simplified model which in turn considers only conductor torsions is the Nigol model (2 DOF). According to Nigol (1974), the following inequality should be met to ensure galloping instability:

$$
\frac{\mathrm{dC}_{\mathrm{M}}}{\mathrm{d} \alpha}<0
$$

where: $\alpha$ is the angle of attack in degrees, $\mathrm{C}_{\mathrm{M}}$ is the aerodynamic moment coefficient.

In practice the galloping phenomenon always become more complicated such as involving dampers attached to conductors with noticeable geometric nonlineariries.

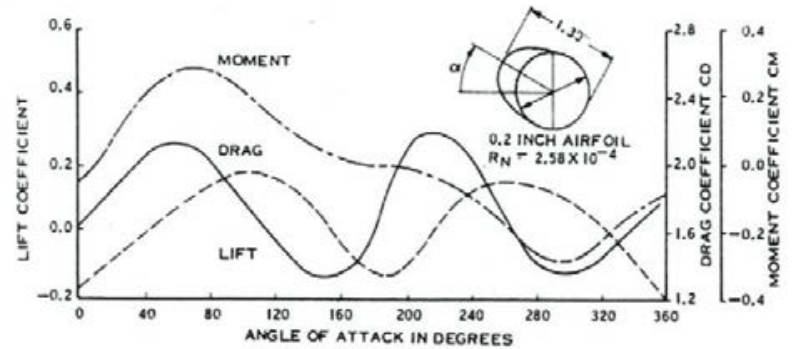

Fig. 2: Effect of lift, drag and moment aerodynamic coefficients on a conductor covered with ice Nigol, 1974)

\section{Antigalloping methods}

The existing methods of reducing vibrations of power lines are as follows:

- aerodynamic-structural methods (designing conductors of a low risk of galloping), e.g. a conductor made from two wires, a self-damping conductor, a conductor of an oval cross section, etc.; 
- mechanical methods - mechanical dampers mounted in conductors. Common damping devices which protect conductors from galloping include: rigid and flexible interphase spacers, spiral spoilers and pendulum dampers.

- ice covering prevention and removal methods.

Ice covering is removed from power line conductors with the following methods:

- heating conductors with alternate current;

- dielectric heating with high frequency currents;

- mechanical removal of ice accretion with a disc moved along the conductor;

- technology based on mechanical effects of the aerodynamic influence of currents in respective conductors of one phase (electrodynamic accretion removal);

- use of hydrophobic material;

- use of laser to melt ice, etc.

AAC/VR (or AASR/VR) conductor is an example of aerodynamic - structural methods (Fig. 3a). This conductor is designed to reduce aeolian vibrations and galloping. The conductor, with a eight-shaped cross-section, consists of two identical twisted wires (Fig. 3b). The spiral shape of this conductor causes a disturbance of the forces generated from the transversely directed wind direction. These forces are disturbed by the constantly changing cross section exposed to the wind. This spiral shape of the cable together with less torsional stiffness and changing bending stiffness reduces the galloping of the cable.

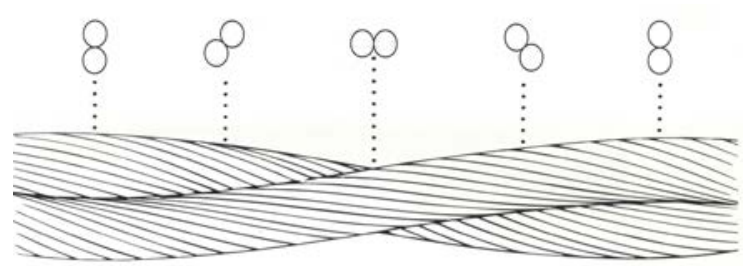

(a)

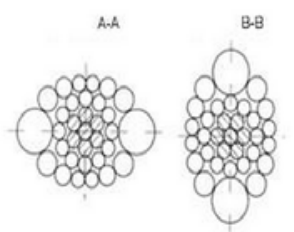

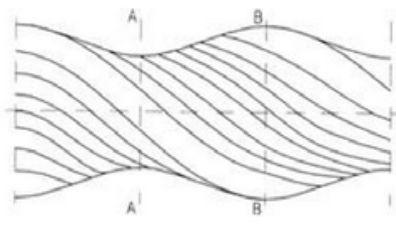

(b)

Fig. 3: (a) Conductor VR2 (Southwire, 2016), (b) Eight-shaped cross-section conductor

(Kiessling, 2003)

A damping effect similar to the above described was obtained for an oval cross-section. Figure 5 shows the cable with variable cross oval cross-section along its entire length, twisted from wires of various diameters.

Understanding of the conductor galloping phenomenon is important not only in theory, but also in the development of the antigalloping methods for overhead power lines. Limiting the level of wind-induced of conductors of electrical lines covered with ice is very important because undamped vibrations may leads to damage to conductor, fitting or failure of the supporting structures.

\section{References}

Den Hertog O. J.P., (1932), Transmission line vibration due to sleet, Transactions of the American Institute of Electrical Engineers 51 (part 4), 1932, 1074-1086.

Farzaneh M., (2008) Atmospheric icing of power networks. Springer.

Fikke S., Ronsten G., Heimo A., Kunz S., Ostrozlik M., Persson P.-E., Sabata J., Wareing B., Wichura B., Chum J., Laakso T., Säntti K., Makkonen L. (2007a), Atmospheric Icing on Structures Measurements and data collection on icing: State of the Art. Bundesamt für Meteorologie und Klimatologie, MeteoSchweiz,

Fikke S. (2007b), State of the art of conductor galloping, COST-727-report, Technical Brochure, 322TF B2. A complementary document to Transmission line reference book -Wind-induced conductor motion. Chapter 4: Conductor galloping,” Based on EPRI Research project 792.

Kiessling F., Nefzger P., FNolasco J.F. , Kaintzyk U. (2003) Overhead Power Lines: Planning, Design, Construction, Springer.

Luongo A., Zulli D., Piccardo G., (2009) On the effect of twist angle on nonlinear galloping of suspended cables. Computers and Structeres 87 (15-16) pp. 1003-1014.

Nigol, G.J. Clarke, (1974) Conductor galloping and control based on torsional mechanism. Proceeding of the IEEE Power Engineering Society Winter Meeting Paper, New York, No. C74016-2.

PES-TR17, (2015) An Introductory Discussion on Aeolian Cibration of Single Conductors prepared by the Transmission \& Distribution Committee. IEEE The Institute of Electrical and Electronic Engineers, Inc.

Southwire, (2016), http://www.southwire.com, at date 30.09.2016.

Stabiloy (2015), www.stabiloy.com, at date.09.2016. 